\title{
Clinical Application of Hyperbaric Oxygen in Treatment of Idiopathic Sudden Sensorineural Hearing Loss
}

\author{
Shin Ae Kim and Joong Ho Ahn \\ Department of Otolaryngology, University of Ulsan College of Medicine, Asan Medical Center, Seoul, Korea
}

돌발성 난청에서 고압산소 치료의 기전, 효과 및 방법

김 신 애·안 중 호

울산대학교 의과대학 서울아산병원 이비인후과학교실

\author{
Received February 2, 2016 \\ Revised April 15, 2016 \\ Accepted April 28, 2016 \\ Address for correspondence \\ Joong Ho Ahn, MD \\ Department of Otolaryngology, \\ University of Ulsan \\ College of Medicine, \\ Asan Medical Center, \\ 88 Olympic-ro 43-gil, Songpa-gu, \\ Seoul 05505, Korea \\ Tel $+82-2-3010-3710$ \\ Fax $+82-2-489-2773$ \\ E-mail meniere@amc.seoul.kr
}

\begin{abstract}
Sudden sensorineural hearing loss is relatively common disease with unknown etiology. Although its etiology is unknown, it is thought to be a common pathway that leads to cochlear ischemia which leads to cochlear damage and hearing loss. Hyperbaric oxygen therapy is one of options for the treatment of sudden hearing loss which exposes patient with 1.5-3 fold sea level pressure of $100 \%$ oxygen which may reverse the ischemic condition of cochlea. According to previous studies, hyperbaric oxygen therapy is beneficial for restoring hearing level in sudden hearing loss patients especially when it is applied at early stage of onset, young age patient and profound hearing loss. Data from Asan medical center with 29 patients with idiopathic sudden sensorineural hearing loss shows $51.7 \%$ of good recovery rate after hyperbaric oxygen treatment. This treatment method however, also has minor complications and is very costly, practitioner should consider the cost-benefit before using this method.
\end{abstract}

Korean J Otorhinolaryngol-Head Neck Surg 2016;59(7):490-4

Key Words Cochlea $\cdot$ Hyperbaric oxygen $\cdot$ Ischemia $\cdot$ Sudden deafness.

\section{서 론}

돌발성 감각신경성 난청은 72 시간 이내에 연속된 세 개 이 상의 주파수에서 $30 \mathrm{~dB}$ 이상의 청력 감소로 정의하며, 인구 10 만 명당 5 10명이 이환되는 질환이다. ${ }^{1)}$ 돌발성 난청의 원인 은 아직 정확히 밝혀진 바가 없으며, 바이러스 감염, 혈액순환 장애, 와우막 파열과 내이 병변 등이 원인으로 추정되고 있다.2)

고압산소요법은 1960년 Boerema 등에 의해 처음으로 소개 된 이후 일산화탄소 중독, 혐기성 세균 감염, 감압병 등 여러 질병을 치료하는 데 이용되어 왔다. ${ }^{2)}$ 1960년대 말 독일과 프랑 스에서 고압산소요법이 돌발성 난청의 치료로 처음으로 활용 된 이후 고압산소요법이 돌발성 난청의 치료 효과가 있다는 임상 연구들이 발표되면서 현재 하나의 치료 도구로 자리매김 하고 있다. ${ }^{3)}$

본 논문에서는 돌발성 난청에서 고압산소 치료의 원리, 적
응증, 치료 효과, 방법 및 부작용에 대하여 논의하고자 한다.

$$
\text { 고압산소 치료의 원리 }
$$

돌발성 난청 중 가장 많은 비중을 차지하는 것이 특발성 돌 발성 난청이며, 이외에도 감염, 외상, 종양, 면역학적 내이 질 병, 혈관 질환 등이 원인으로 알려져 있다. 이들 중 와우로의 혈류 감소와 와우의 허혈이 일부 돌발성 난청의 원인이자 다 양한 원인으로 인한 청력 감소의 최종적인 공통 경로로 추정 되고 있다. 고압산소 요법은 조직내 산소 전달이 충분히 되도 록 돕는 치료로서, 돌발성 난청에서 내이의 허혈상태를 완화 시킴으로써 허혈에 민감한 기관인 와우 손상을 막는 역할을 할 것으로 여겨진다.

혈액내에서 산소는 두 가지 형태로 운반된다. 한 가지는 헤 모글로빈에 결합한 형태이며, 이 형태로는 산소가 모세혈관을 
투과할 수 없다. 다른 한 가지는 혈액내 용해된 형태의 산소인 데, 이는 모세혈관을 잘 통과하며 헤모글로빈 수치와 상관 없 이 독립적으로 용해되고, 운반된다.

산소의 농도를 높이면 헤모글로빈과 결합한 산소 비율을 높 일 수 있고, 산소의 압력을 높이면 혈청 내 용해되는 산소의 양을 늘릴 수 있다. 고압산소 치료는 $100 \%$ 산소를 대기압의 2 3배의 압력으로 만든 공간에 환자를 노출시킴으로써 체내 산소 결합 헤모글로빈 포화도를 $100 \%$ 로 올리게 되며 동맥 산 소압을 $2000 \mathrm{~mm} \mathrm{Hg}$, 조직 산소압을 $400 \mathrm{~mm} \mathrm{Hg}$ 까지 높일 수 있다. ${ }^{4}$ 대기압에서 혈청 산소 농도는 $0.3 \mathrm{~mL} / \mathrm{dL}$ 이다. 휴식 상태에서 조직은 일반적으로 5 6 mL/dL의 산소를 혈액으로 부터 가져온다. 1 기압하 $100 \%$ 산소를 제공하면 동맥 내 산소 분압은 5 배 증가하며 혈청 내 용해되는 산소 농도는 $2 \mathrm{~mL} / \mathrm{dL}$ 가 된다. $100 \%$ 산소를 3 기압으로 가압했을 때에는 혈청 내 산 소 농도가 $6.6 \mathrm{~mL} / \mathrm{dL}$ 가 된다(Fig. 1). 이를 통해 헤모글로빈에 결합되어 운반된 산소 없이도 충분히 체내 허혈성 병변에 산 소 공급을 원활히할 수 있다.

고압산소 치료의 효과에는 크게 세 가지가 있다. 첫 번째는 압력 효과로 체내에 발생한 기체 형태의 비활성 가스의 용적 을 줄여주며, 산소로 대체하여 혈액으로 용해되게 만든다. 이 는 공기색전증의 치료로 이용된다. 두 번째로 혈액내 산소 분

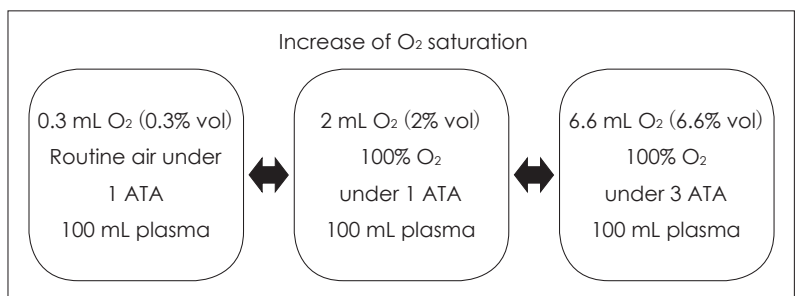

Fig. 1. Figure shows how to increase oxygen saturation. While 0.3 $\mathrm{mL}$ of oxygen ( $0.3 \%$ volume) is dissolved in $100 \mathrm{~mL}$ plasma under the routine air condition, we can increase the amount of dissolved oxygen up to $2 \%$ volume with using $100 \%$ oxygen. When we press the air up to 3 ATA, oxygen will be dissolved up to $6.6 \mathrm{~mL}$ in $100 \mathrm{~mL}$ plasma (6.6\% volume). ATA: absolute atmosphere.
압을 높혀 즉각적으로 조직 저산소증을 해소시키는 역할을 한다. 마지막으로 생화학적으로 조직관류를 돕고, 산소 라디 칼을 이용한 호중구의 항 박테리아 작용을 촉진하고, 조직 재 생과 신생혈관 생성을 촉진시키는 작용이 있다. ${ }^{5)}$

\section{돌발성 난청에서 고압산소 치료의 적응증 및 임상적 효과}

2012년 American Academy of Otolaryngology-Head and Neck Surgery 돌발성 난청 치료 가이드라인에 따르면 돌발성 난청의 초치료로서 스테로이드 요법과 고압산소 치료가 선택 사항으로 임상의의 판단과 환자의 선호도를 고려하여 치료여 부를 결정하도록 권고되어 있다. ${ }^{6}$ 그러나 고압산소 요법은 현 재 임상적으로 흔히 사용되고 있지는 않으며 보통 스테로이드 요법에 부가적으로 시행된다. 현재까지의 연구 결과들을 종합 하여 볼 때, 돌발성 난청에 대한 고압산소 치료는 젊은 연령 (50 60세 미만)에서 발병 초기(발병 2주 3개월 이내)에 시행 할수록, 그리고 청력 손실이 $60 \mathrm{~dB}$ 이상인 환자에서 효과가 좋은 것으로 나타났다. ${ }^{7-12)}$

2012년 개정된 Cochrane 메타분석에 따르면, 1985년부터 2012년까지 이루어진 모든 무작위 통제 연구를 조사하였을 때 총 7건의 연구(397명의 환자)가 분석에 포함되었으며 고압 산소 치료가 청력을 $25 \%$ 향상시키는 데 유의한 효과가 있으 며, 대조군에 비해 청력 회복률을 $22 \%$ 높이는 것으로 나타났 다. 그러나 이에 대한 임상적 유용성은 확립되지 못하였다. 또 한 발병일로부터 6개월 이상 경과한 환자에서는 유의한 효과 가 없는 것으로 나타나 이런 환자들에서는 고압산소 치료가 권장되지 않는다. ${ }^{13)}$

Cochrane review에 포함되지 않은 연구 중 36명의 환자를 대상으로 한 무작위 대조 연구에서는 고압산소 치료군에서 치 료성적의 의미 있는 차이를 보이지 않았다. ${ }^{14)}$ 마찬가지로 Ersoy

Table 1. Characteristics of reviewed randomized controlled studies

\begin{tabular}{|c|c|c|c|c|}
\hline Author & Year & No. of participants & $\mathrm{HBO}$ treatment method & Benefit of $\mathrm{HBO}$ \\
\hline Cavallazzi, et al. ${ }^{17)}$ & 1996 & 64 & 60 min QD 15 times & Statistically significant \\
\hline Fattori, et al. ${ }^{18)}$ & 2001 & 50 & 90 min QD 10 times & Statistically significant \\
\hline Hoffmann, et al. ${ }^{19)}$ & 1995 & 44 & $45 \mathrm{~min}$ QD $10-20$ times & Statistically significant \\
\hline Schwab, et al. ${ }^{22)}$ & 1998 & 20 & 45 min QD $10-20$ times & Statistically significant \\
\hline Hoffmann, et al. ${ }^{20)}$ & 1995 & 75 & $45 \mathrm{~min}$ QD $10-20$ times & Statistically significant \\
\hline Pilgramm, et al. ${ }^{21)}$ & 1985 & & & Statistically significant \\
\hline Topuz, et al. ${ }^{11)}$ & 2004 & 51 & 90 min QD-BID 25 times & Statistically significant \\
\hline Cekin, et al. ${ }^{14)}$ & 2009 & 36 & 90 min QD 10 times & $\begin{array}{l}\text { Better result in } \mathrm{HBO} \text { group } \\
\text { but statistically insignificant }\end{array}$ \\
\hline Ersoy Callioglu, et al. ${ }^{15)}$ & 2015 & 44 & 90 min QD 10 times & $\begin{array}{l}\text { Better result in } \mathrm{HBO} \text { group } \\
\text { but statistically insignificant }\end{array}$ \\
\hline
\end{tabular}

QD: quaque die, HBO: hyperbaric oxygen 
Callioglu 등 ${ }^{15}$ 의 연구에서도 고압산소요법과 스테로이드 치 료의 병용이 스테로이드만 사용한 환자와 치료 효과면에서 의미 있는 차이가 없었다. 반대로 44명의 초치료 실패 환자를 대상으로 한 전향적 무작위 대조군 시험에서는 고압산소 치 료군이 유의하게 치료 효과가 있는 것으로 나타났다. ${ }^{16)} \mathrm{Table}$ 1 은 현재까지 시행된 무작위 환자-대조군 연구의 방법 및 결 과이다. ${ }^{11,14,15,17-22)}$

임상적 효과에 대한 기존 연구들의 한계점은 각각의 연구 에서 치료 방법이 통일되지 않았다는 점과 치료 효과를 분석 하는 방법이 통일되지 않았으며 각각의 한계점을 가지고 있다 는 것이다. ${ }^{23)}$

\section{고압산소 치료의 방법}

돌발성 난청에 대한 고압산소 치료는 일반적으로 $100 \%$ 산 소 챔버를 1.5 3기압으로 가압하여 회당 60 120분으로 하루 1 2회, 총 20 40회 시행한다.

산소 챔버에는 단실 챔버(mono-place chamber)와 복실 챔 버(multi-place chamber)가 있다. 단실 챔버(Fig. 2)는 한번에 한 명만 이용할 수 있으며 아크릴로 된 창이 있는 것이 특징이 다. 챔버는 산소만을 이용하여 가압이 되어 마스크를 이용하 지 않아도 고농도의 산소의 흡입이 가능하며, 약 3 기압까지 가 압이 가능하다. 이용자의 편의를 위하여 의료진과 의사소통 이 가능한 인터폰과 챔버 내 기압 및 온도를 볼 수 있는 장치 가 장비 내부에 설치되어 있다. 복실 챔버는 2명 이상이 동시 에 치료받을 수 있는 구조로, 챔버가 철제로 이루어져 있고, 환자와 의료진이 동행하여 챔버에 들어간다. 챔버 내 가압을 위하여 공기를 사용하며, 환자는 챔버 내에서 마스크 또는 밀 폐 후드를 통하여 고압산소를 흡입한다. 복실 챔버 내 기압은 6 기압까지 가압 가능하다. 단실 챔버가 상대적으로 비용 및 의료 인력이 적게 소요되어 현재 국내 및 해외에 복실 챔버에

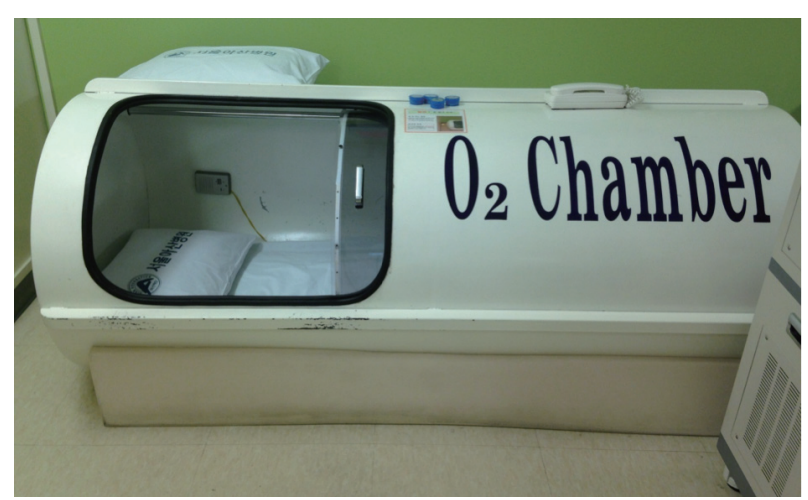

Fig. 2. Average of pre- and post-treatment PTA of patients treated with hyperbaric $\mathrm{O}_{2}$ and systemic steroid with or without intratympanic steroid in Asan Medical Center. PTA: pure tone audiometry.
비해 많이 보급되어 있는 실정이다.

\section{부작용 및 사회적 비용}

일반적인 치료 프로토콜인 3기압 이내로의 가압과 회당 120 분 이내의 치료 시간을 잘 지킨다면 고압산소 치료는 안전 하다. 고압산소 치료로 인한 중증의 부작용은 알려진 바 없으 나, 경한 부작용은 존재한다. 가장 흔한 부작용은 이관 기능 장애로 인한 이충만감이며, 다양한 이유로 고압산소 치료를 받은 782 명의 환자를 대상으로 한 연구에서 $17 \%$ 의 환자가 이 충만감을 경험하였다고 보고된 바 있다. ${ }^{24)}$ 이충만감은 중이내 압력과 외부 압력의 차이에 의해 발생하는데, 고압산소 치료 중에는 일시적으로 중이내 음압이 발생하나, 이관 기능이 정 상인 환자에서는 이관을 통해 압력 균형을 맞출 수 있다. 반 대로, 고압산소 치료 후 다시 감압할 때에도 일시적으로 중이 내 양압이 발생하나 이관을 통해서 압력차가 사라진다. 그러 나 이관 기능 장애가 있는 환자에서는 산소 챔버 안에서 중이 내 음압이 발생하여도 빠르게 음압을 해소하지 못하고, 반대 로 챔버에서 나올 때에는 양압 상태가 지속되는 등의 문제가 발생하여 지속적으로 이충만감을 느낄 수 있다.

이외 일반적인 부작용에는 산소가 유리체에 작용하여 발생 하는 일시적인 근시, 급격한 압력 변화로 중이 또는 부비동, 드 물게는 치아나 폐에 발생하는 통증이 있다. 고농도의 산소가 대발작을 일으키기도 하지만 이는 매우 드물며, 영구적 뇌손 상을 일으키지 않고 저절로 회복된다. ${ }^{25}$ 고압산소 치료를 반복 적으로 시행하는 환자들에서 일시적인 가슴답답함, 가슴 작 열감, 기침 등이 발생할 수 있다. 또한 대기압에서 산소치료를 오래 받은 기왕력이 있는 환자들에서 고압산소 치료를 시행했 을 때 산소로 인한 폐독성이 나타날 위험성이 높아진다. 폐쇄 공포증이 있는 환자들의 경우에는 단실 챔버를 이용한 치료 에 제한이 있다. ${ }^{26)}$

고압산소 치료는 시간과 비용이 많이 드는 치료이다. 일반적 으로 1회 치료에 1 시간 정도 소요되는 치료를 하루 1 2회, 5 10일간 시행하게 되는데 서울아산병원 기준으로 시간당 4 만 원가량 환자에게 부담된다. 그러므로 치료로 인한 이득과 손실을 고려했을 때 비용적인 측면은 치료 결정 시 꼭 고려되 어야 하며 환자와 사전 협의되어야 할 사항이다. 마지막으로 고압산소 치료를 위한 시설이 갖추어진 병원이 제한적이라는 점도 치료의 한계점이다.

\section{서울아산병원의 경험}

2014년 1월부터 2015년 12월까지 서울아산병원에서 특발성 
Table 2. Patient demographics of patients treated with hyperbaric $\mathrm{O}_{2}$ and systemic steroid with or without intratympanic steroid in Asan Medical Center $(n=29)$

\begin{tabular}{|c|c|c|}
\hline Variables & $\mathrm{HBO}$ group & Control group \\
\hline \multicolumn{3}{|l|}{ Sex, n (\%) } \\
\hline Male & $15(51.7)$ & $13(44.8)$ \\
\hline Female & $14(48.3)$ & $16(55.2)$ \\
\hline Median age, year (range) & $51(14-88)$ & $49(19-78)$ \\
\hline Initial PTA average (dB) & 87.4 & 73.8 \\
\hline \multicolumn{3}{|l|}{ Hearing loss grade, n (\%) } \\
\hline Mild & $0(0)$ & $0(0)$ \\
\hline Moderate & $7(24.1)$ & $14(48.3)$ \\
\hline Severe & $11(37.9)$ & $9(31.0)$ \\
\hline Profound & 11 (37.9) & $6(20.7)$ \\
\hline
\end{tabular}

PTA: pure tone audiometry, $\mathrm{HBO}$ : hyperbaric oxygen

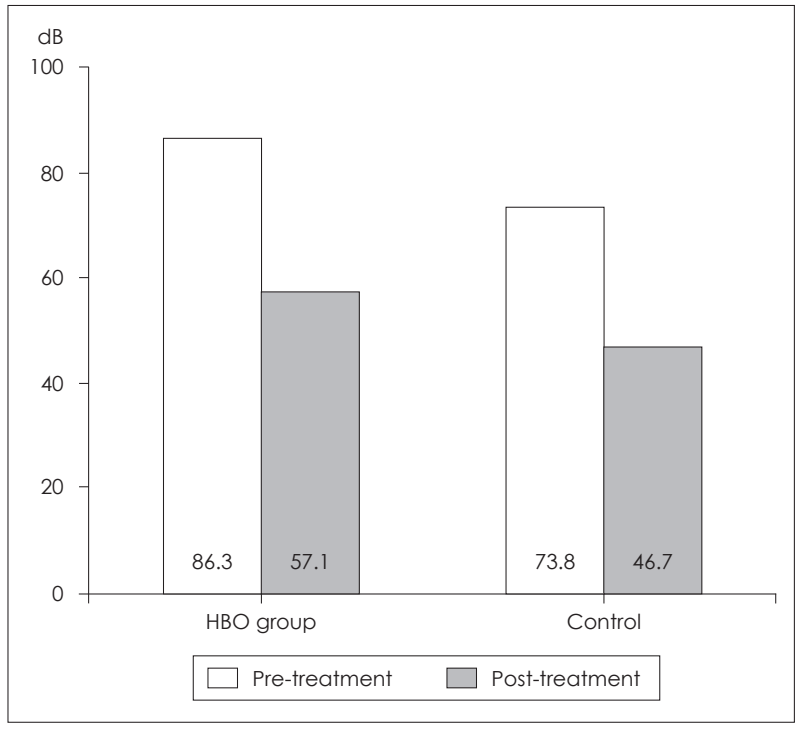

Fig. 3. Mono-place hyperbaric $\mathrm{O}_{2}$ chamber.

돌발성 난청으로 진단받고 경구 스테로이드 요법과 병용하여 고압산소 요법을 시행한 29 명의 환자의 치료 결과를 후향적 으로 분석하였다. 29 명의 환자 중 남자 15 명, 여자 14 명이었 으며, 이 중 한 명의 환자에서 양측이 이환되었다. 발병 시 연 령의 중간값은 51세, 발병일로부터 고압산소 치료 시작까지 의 기간은 평균 9.4일이었다. 환측 귀의 발병 시 pure tone audiometry(PTA) 평균값은 $87.4 \mathrm{~dB}$ 이며 76\%의 환자에서 발병 시 $70 \mathrm{~dB}$ 이상의 청력 역치를 나타냈다(Table 2).

29명의 환자에서 초치료로 경구 스테로이드와 함께 고압산 소 요법을 시행하였고, 1 명의 환자에서는 경구 스테로이드 요 법 이후 구제 요법으로 고압산소 요법을 시행하였으며 29명 중 21명에서 중이 내 스테로이드 주사요법을 병용하였다. 고압 산소요법은 12 명의 환자에서 1 일 2회, 17 명의 환자에서 1 일 1 회, 모든 증례에서 회당 1 시간 시행되었으며 총 시행 횟수는 2 회에서 23회까지 다양하였다.
Table 3. PTA recovery of study ears

\begin{tabular}{lcc}
\hline Recovery grade, $\mathrm{n}(\%)$ & HBO group $(\mathrm{n}=30)$ & Control $(\mathrm{n}=29)$ \\
\hline Complete & $3(10)$ & $5(17)$ \\
Good & $12(40)$ & $6(21)$ \\
Fair & $6(20)$ & $10(34)$ \\
Unchanged & $9(30)$ & $8(31)$ \\
\hline
\end{tabular}

PTA: pure tone audiometry, $\mathrm{HBO}$ : hyperbaric oxygen

치료 전후 주파수별 청력역치 평균값은 Fig. 3과 같다. 치료 전 평균 순음 청력역치는 $87.4 \mathrm{~dB}$, 치료 후는 $59.2 \mathrm{~dB}$ 이었다. 한 명의 환자에서 양측이 이환되어 총 30 환측에 대한 청력역 치 결과값을 분석하였을 때 3 명의 환자에서 치료 후 청력의 완전 회복을 보였으며, 12 명에서 평균 $30 \mathrm{~dB}$ 이상의 PTA 상 승, 6 명에서 $10 \mathrm{~dB}$ 이상 $30 \mathrm{~dB}$ 미만의 청력 호전을 보였으며, 9 명에서는 치료 전후 청력 변화가 없었다. 같은 기간 본원에서 고압산소 치료를 하지 않은 환자 29명의 치료 성적을 비교하 였을 때 good recovery 이상의 치료율이 고압산소를 한 환자 에서 $51.7 \%$, 경구 스테로이드 및 고실 내 스테로이드 요법만 한 환자에서 $38.0 \%$ 로 더 좋은 결과를 나타냈으나 통계학적 유의 성은 없었다 $(p=0.315)$ (Table 3). 두 군의 치료 전후 어음명료도 차이를 비교해 보았을 때에도 고압산소 치료군에서 평균 $38 \%$, 대조군에서 $27 \%$ 의 어음명료도 호전을 나타내 치료군에 서 더 좋은 성적을 나타냈으나 통계학적으로는 유의하지 않았 다 $(p=0.288) .29$ 명의 고압산소 치료군에서 고압산소 부작용이 발생한 사례는 없었다.

본 연구의 한계점은 치료군에서 환자들마다 treatment regimen에 차이가 있다는 점이다. 환자마다 다르게 시행된 고압산 소 치료 횟수와 고실 내 스테로이드 주입술 병용 유무는 치료 효과에 영향이 있을 것으로 보이나, 환자 수가 적어 변인 통제 후 통계학적 결과를 도출하는 데에는 한계가 있었다. 또한, 추 적관찰 기간이 2 개월에서 1년 2개월로 비교적 추적관찰 기간 이 짧아, 향후 장기적 예후 관찰이 필요하다.

본원의 치료 결과를 종합하면, 중등도 이상의 청력저하가 있는 돌발성 난청 환자 29 명 중 $51.7 \%$ 의 환자에서 $30 \mathrm{~dB}$ 이상 의 순음 청력역치의 회복을 보였다. 대조군과 비교하였을 때 통계학적으로 유의하지는 않았으나 회복률이 더 높았으며, 향 후 전향적 연구를 통하여 임상적 유용성을 밝혀야 할 것이다.

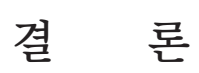

돌발성 난청 환자에서 발병 초기에 고압산소 치료를 시행하 는 것이 임상적 효과가 있는 것으로 보인다. 그러나 고압산소 치료는 시간과 비용이 많이 들고, 경한 부작용이 존재하며, 치 료 횟수나 빈도에 대한 정의는 아직 뚜렷이 정립된 바가 없다. 
앞으로 이에 대한 지속적인 관심과 연구가 필요하다.

\section{REFERENCES}

1) Mattox DE, Simmons FB. Natural history of sudden sensorineural hearing loss. Ann Otol Rhinol Laryngol 1977;86(4 Pt 1):463-80.

2) Shaia FT, Sheehy JL. Sudden sensori-neural hearing impairment: a report of 1,220 cases. Laryngoscope 1976;86(3):389-98.

3) Bennett MH, Kertesz T, Yeung P. Hyperbaric oxygen for idiopathic sudden sensorineural hearing loss and tinnitus. Cochrane Database Syst Rev 2007;(1):CD004739.

4) Lambertsen CJ, Dough RH, Cooper DY, Emmel GL, Loeschcke $\mathrm{HH}$, Schmidt CF. Oxygen toxicity; effects in man of oxygen inhalation at 1 and 3.5 atmospheres upon blood gas transport, cerebral circulation and cerebral metabolism. J Appl Physiol 1953;5(9):471-86.

5) Gill AL, Bell CN. Hyperbaric oxygen: its uses, mechanisms of action and outcomes. QJM 2004;97(7):385-95.

6) Stachler RJ, Chandrasekhar SS, Archer SM, Rosenfeld RM, Schwartz SR, Barrs DM, et al. Clinical practice guideline: sudden hearing loss. Otolaryngol Head Neck Surg 2012;146(3 Suppl):S1-35.

7) Liu SC, Kang BH, Lee JC, Lin YS, Huang KL, Liu DW, et al. Comparison of therapeutic results in sudden sensorineural hearing loss with/without additional hyperbaric oxygen therapy: a retrospective review of 465 audiologically controlled cases. Clin Otolaryngol 2011; 36(2):121-8.

8) Fetterman BL, Saunders JE, Luxford WM. Prognosis and treatment of sudden sensorineural hearing loss. Am J Otol 1996;17(4):529-36.

9) Cvorović L, Deric D, Probst R, Hegemann S. Prognostic model for predicting hearing recovery in idiopathic sudden sensorineural hearing loss. Otol Neurotol 2008;29(4):464-9.

10) Fujimura $T$, Suzuki H, Shiomori $T$, Udaka $T$, Mori $T$. Hyperbaric oxygen and steroid therapy for idiopathic sudden sensorineural hearing loss. Eur Arch Otorhinolaryngol 2007;264(8):861-6.

11) Topuz E, Yigit O, Cinar U, Seven H. Should hyperbaric oxygen be added to treatment in idiopathic sudden sensorineural hearing loss? Eur Arch Otorhinolaryngol 2004;261(7):393-6.

12) Capuano L, Cavaliere M, Parente G, Damiano A, Pezzuti G, Lopardo D, et al. Hyperbaric oxygen for idiopathic sudden hearing loss: is the routine application helpful? Acta Otolaryngol 2015;135(7):692-7.

13) Bennett MH, Kertesz T, Perleth M, Yeung P, Lehm JP. Hyperbaric oxygen for idiopathic sudden sensorineural hearing loss and tinnitus. Cochrane Database Syst Rev 2012;10:CD004739.

14) Cekin E, Cincik H, Ulubil SA, Gungor A. Effectiveness of hyperbaric oxygen therapy in management of sudden hearing loss. J Laryngol Otol 2009;123(6):609-12.

15) Ersoy Callioglu E, Tuzuner A, Demirci S, Cengiz C, Caylan R. Comparison of simultaneous systemic steroid and hyperbaric oxygen treatment versus only steroid in idiopathic sudden sensorineural hearing loss. Int J Clin Exp Med 2015;8(6):9876-82.

16) Pezzoli M, Magnano M, Maffi L, Pezzoli L, Marcato P, Orione M, et al. Hyperbaric oxygen therapy as salvage treatment for sudden sensorineural hearing loss: a prospective controlled study. Eur Arch Otorhinolaryngol 2015;272(7):1659-66.

17) Cavallazzi G, Pignataro L, Capaccio P. Italian experience in hyperbaric oxygen therapy for idiopathic sudden sensorineural hearing loss. In: Marroni A, Oriani G, editors. Proceedings of international joint meeting on hyperbaric and underwater medicine. Milano: Instituto ortopedico Galeazzi;1996. p.647-9.

18) Fattori B, Berrettini S, Casani A, Nacci A, De Vito A, De Iaco G. Sudden hypoacusis treated with hyperbaric oxygen therapy: a controlled study. Ear Nose Throat J 2001;80(9):655-60.

19) Hoffmann G, Böhmer D, Desloovere C. Hyperbaric oxygenation as a treatment of chronic forms of inner ear hearing loss and tinnitus. In: Li W, Cramer FS, editors. Proceedings of the eleventh international congress of hyperbaric medicine. Flagstaff: Best Publishing;1995. p.141-5.

20) Hoffmann G, Böhmer D, Desloovere C. Hyperbaric oxygenation as a treatment for sudden deafness and acute tinnitus. In: Li W, Cramer FS, editors. Proceedings of the eleventh international congress of hyperbaric medicine. Flagstaff: Best Publishing;1995. p.146-51.

21) Pilgramm M, Lamm H, Schumann K. [Hyperbaric oxygen therapy in sudden deafness]. Laryngol Rhinol Otol (Stuttg) 1985;64(7):351-4.

22) Schwab B, Flunkert C, Heermann R, Lenarz T. HBO in the therapy of cochlear dysfunction: first results of a randomized study. EUBS diving and hyperbaric medicine, collected manuscripts of XXIV annual scientific meeting of the European underwater and baromedical society. Stockholm: EUBS;1998. p.40-2.

23) Halpin C, Rauch SD. Using audiometric thresholds and word recognition in a treatment study. Otol Neurotol 2006;27(1):110-6.

24) Plafki $C$, Peters $P$, Almeling M, Welslau W, Busch R. Complications and side effects of hyperbaric oxygen therapy. Aviat Space Environ Med 2000;71(2):119-24.

25) Clark JM, Lambertsen CJ. Pulmonary oxygen toxicity: a review. Pharmacol Rev 1971;23(2):37-133.

26) Tibbles PM, Edelsberg JS. Hyperbaric-oxygen therapy. N Engl J Med 1996;334(25):1642-8. 